\title{
Evaluation of human T-lymphotropic virus prevalence/co-infection rates for a four-year period in a non-metropolitan blood center in Southeast Brazil
}

\author{
Mariana Tomazini Pinto ${ }^{[1],[2], ~ S v e t o s l a v ~ N a n e v ~ S l a v o v ~[1], ~ V a n d e r l e ́ i a ~ B a ́ r b a r o ~ V a l e n t e ~}{ }^{[1],}$ \\ Eugênia Maria Amorim Ubiali ${ }^{[1]}$, Dimas Tadeu Covas ${ }^{[1],[3]}$ and Simone Kashima ${ }^{[1],[2]}$
}

[1]. Fundação Hemocentro de Ribeirão Preto, Faculdade de Medicina de Ribeirão Preto, Universidade de São Paulo, Ribeirão Preto, São Paulo, Brasil.

[2]. Biociências Aplicadas à Farmácia, Faculdade de Ciências Farmacêuticas de Ribeirão Preto, Universidade de São Paulo, Ribeirão Preto, São Paulo, Brasil.

[3]. Departamento de Clínica Médica, Faculdade de Medicina de Ribeirão Preto, Universidade de São Paulo, Ribeirão Preto, São Paulo, Brasil.

\begin{abstract}
Introduction: Human T-lymphotropic virus types 1/2 (HTLV-1/2) are distributed worldwide and are endemic in specific regions. Methods: Serological evaluation of the HTLV-1/2 prevalence and co-infection rate [human immunodeficiency virus (HIV), hepatitis B virus (HBV), hepatitis C virus (HCV), Chagas disease, and syphilis)] for 2011-2014 was performed with volunteer blood donors from the western part of São Paulo State. Results: Serrana and Araçatuba had higher HTLV seroprevalence rates (0.1\%); while Franca, Olimpia, and Bebedouro had lower seroprevalences $(0.04 \%)$. Co-infection (HBV and syphilis) was present in $12.3 \%$ of HTLV-infected blood donors. Conclusions: Our findings provide data for the prevalence of HTLV in Brazil and demonstrate the importance of regional and global hemovigilance.
\end{abstract}

Keywords: HTLV-1/2 seroprevalence. HTLV-1/2 co-infection. Brazil.

Human T-cell lymphotropic virus type 1 (HTLV-1) is the etiological agent of two distinct clinical conditions: adult T-cell leukemia and HTLV-1-associated myelopathy/tropical spastic paraparesis, which both can evolve in $<5 \%$ of infected individuals. The reason for the development of a clinically manifested disease in only a small percentage of the infected patients is currently unknown, and despite the serious effect of HTLV-1 on compromised individuals, the infection is still regarded as neglected. In addition, whether the other viral variant HTLV-2 is involved in any clinical manifestation remains unknown ${ }^{(1)}$.

More than 20 million people globally are estimated to be infected by HTLV-1. Although HTLV-1 has been restricted to specific geographic regions such as Central and West Africa, Central and South America, the Caribbean, and Japan, a growing number of viral infections has been continuously reported among blood donors in the USA and Europe ${ }^{(2)}$. In Europe (excluding Romania), HTLV-1 transmission has been commonly restricted to immigrants from endemic areas, principally the Caribbean and sub-Saharan Africa. Yet, in many European countries (Italy, Spain, and Germany), HTLV screening in blood donors is not performed, and the prevalence of this virus in Europe is far from being $\mathrm{known}^{(2)}$. Of the Latin American countries, which are

Corresponding author: Dra. Simone Kashima.

e-mail: skashima@hemocentro.fmrp.usp.br

Received 14 August 2015

Accepted 23 December 2015 endemic for HTLV-1, Brazil has the highest absolute number of positive individuals. However, due to the extensive geographical area of the country and its contrasting cultural and demographic characteristics, the seroprevalence of HTLV-1 in Brazil varies significantly in the different geographic regions. For example, in the Northeastern city of Salvador, which has an extensive African influence, the seroprevalence is $1.35 \%{ }^{(3)}$, while in Florianopolis (Southern Brazil), it is only $0.08 \%{ }^{(3)}$. This variation in the HTLV1 prevalence in Brazil raises serious questions regarding the evaluation of the real transfusion-transmission risk of HTLV-1 infection among the distinct populations in the country and its impact on blood donation. This is particularly important because people infected with HTLV-1 by blood transfusion are more prone to clinically manifested conditions ${ }^{(4)}$.

The objective of our study was to evaluate the prevalence of HTLV-1/2 in volunteer blood donors in a non-metropolitan blood center in the southeast part of Brazil, which encompasses the blood collection in the whole western part of the State of São Paulo. These results can contribute to the understanding of the prevalence of this endemic virus in Brazil and highlight specific transmission models involving blood transfusion and/ or hemoderivatives.

The Regional Blood Center of Ribeirão Preto is responsible for the serological screening of blood samples from the whole western part of the state. In addition to the screened area of Ribeirão Preto city, routine screening of blood samples from the municipalities of Serrana, Batatais, Fernandópolis, Franca, Presidente Prudente, Araçatuba, Olímpia, and Bebedouro is performed (Figure 1). 


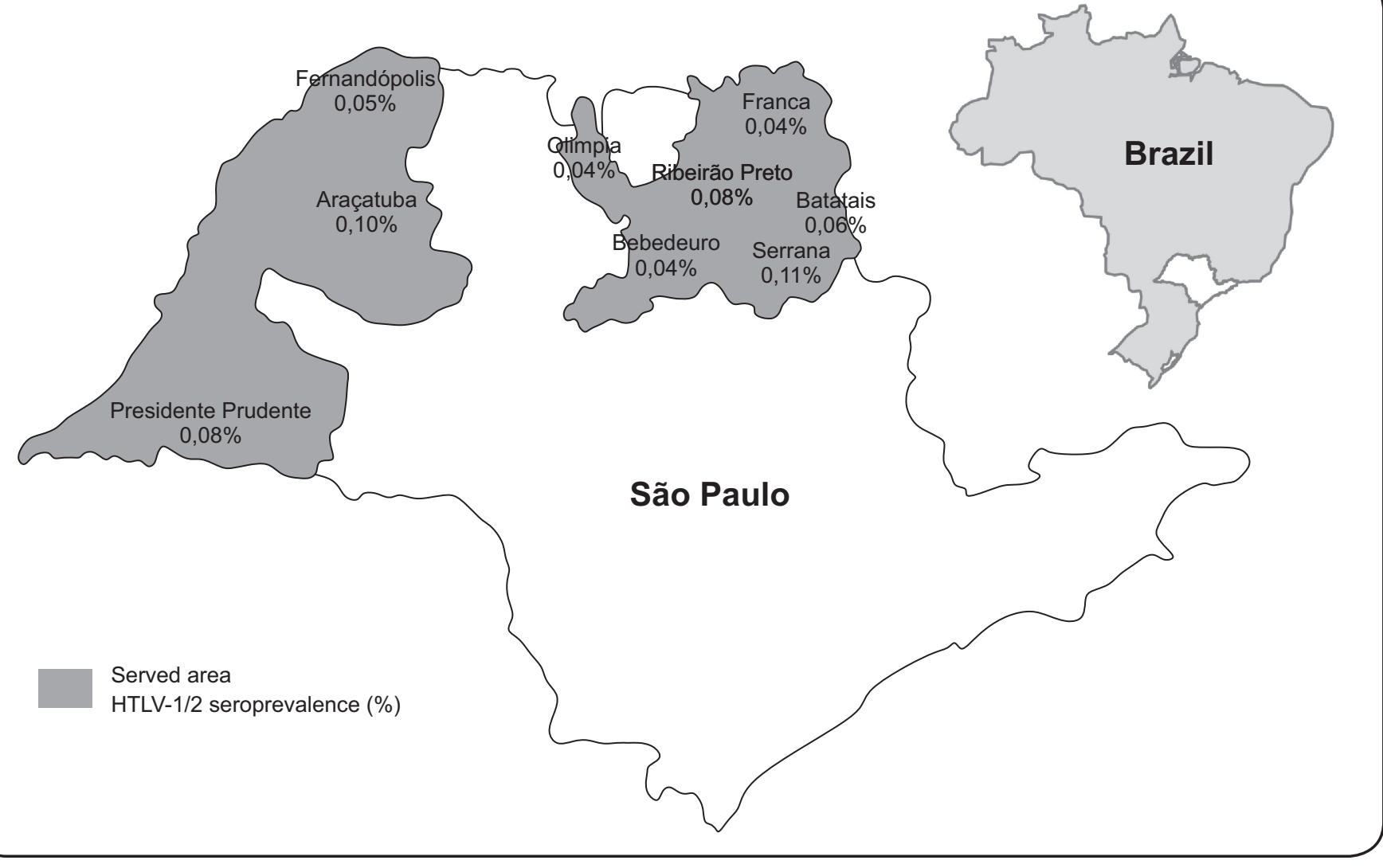

FIGURE 1 - Map of the State of São Paulo, demonstrating its relative geographic position in Brazil and the human T-lymphotropic virus types 1/2 seroprevalence by municipality. HTLV-1/2: human T-lymphotropic virus type 1 and type 2 .

From January 2011 to December 2014, all blood samples were regularly tested for HTLV-1/2 infection. Other mandatory tests were also performed for the following blood-borne pathogens: hepatitis B virus (HBV), hepatitis C virus (HCV), human immunodeficiency virus (HIV), Trypanosoma cruzi (American trypanosomiasis), and Treponema pallidum (syphilis).

The inclusion criteria for the blood donors were age of 18-65 years, absence of clinically overt infectious disease, no report of risky behaviors [e.g., intravenous drug user (IDU)], unsafe sexual practices), and no history of blood/hemoderivative transfusion in the previous 10 years. Donors were also classified according to the number of donations as first-time, lapsed (donated $\leq 1$ time per year), or regular (donated $\geq 2$ times per year).

The initial screening for the presence of HTLV infection was performed using an enzyme immunoassay (EIA). AntiHTLV-1/2 immunoglobulin G (IgG) screening tests were performed with serum using the EIA (Murex Biotech Ltd, Dartford, UK), according to the manufacturer's instructions. Anti-HTLV IgG-reactive or indeterminate samples (based on the pre-determined cut-off value) in the primary test underwent a second EIA.-

The HTLV-1/2 seroprevalence was obtained by dividing the number of the first-time HTLV-1/2-seropositve donors by the total number of first-time blood donations collected in each year. The first-time blood donors who were positive for antiHTLV-1/2 IgG were subsequently evaluated for the presence of co-infections.

Blood donor gender and age were compared by year using Chi-square $\left(\chi^{2}\right)$ tests. To investigate the prevalence by age, we divided the first-time blood donors reactive for HTLV-1/2 into four age groups: $18-29,30-39,40-49$, and $\geq 50$ years. To compare the HTLV prevalence between the different blood collection branches in the region, we evaluated the total donations and first-time donations reactive for HTLV-1/2 during 2011-2014. GraphPad Prism v.5 software (GraphPad Software Inc., San Diego, CA, USA) was used for all analyses, and the level of significance was set at $\mathrm{p} \leq 0.05$.

In the Regional Blood Center of Ribeirão Preto, State of São Paulo, Brazil in 2011-2014, 377,243 blood donors were tested for anti-HTLV-1/2 IgG. During the study period, 71 blood donors $(0.02 \%)$ reacted positively for anti-HTLV-1/2 IgG, representing the overall seroprevalence rate. During the same period, of the 88,330 first-time blood donations ( $23.4 \%$ of the total number of donations), $65(0.07 \%)$ were positive for anti-HTLV-1/2 IgG. The yearly distribution (2011-2014) of the HTLV-1/2 seroprevalence among the volunteer first-time blood donors is shown in Table 1.

Table 1 shows the mean age of the 65 first-time blood donors with HTLV-1/2-reactive samples was 37.6 years (range, $19-63$ years), and the majority $(25 / 65,38 \%)$ were young 


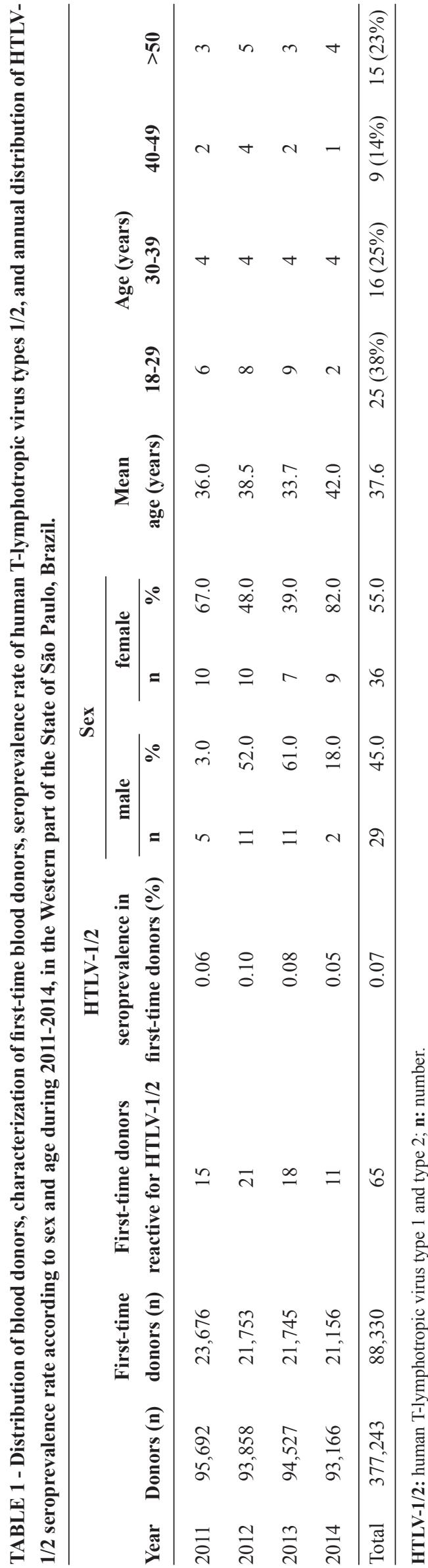

(18-29 years old). In general, the mean HTLV-1/2 seroprevalence was generally higher in female first-time donors $(55 \%)$ than in male first-time donors $(p<0.09)$. However, the HTLV- $1 / 2$ seroprevalence was higher in female first-time donors in 2011 $(67 \%)$ and $2014(82 \%)$ than in male first-time donors $(\mathrm{p}=0.06)$. In 2012 and 2013, the HTLV-1/2 seroprevalence was higher in male first-time donors ( $52 \%$ and $61 \%$, respectively). The sex distribution and age of the donors were not significantly different (results not shown).

As shown in Table 2 and Figure 1 a higher seroprevalence was observed among volunteer blood donors from Serrana $(0.11 \%)$ and Araçatuba cities $(0.10 \%)$. However, the higher prevalence in Serrana seems to be extrapolated from the lower number of donations (one positive result for the whole study period). The lowest prevalences were present in Franca, Olimpia, and Bebedouro municipalities (all, 0.04\%).

The evaluation of HTLV co-infection rates in first-time blood donors resulted in 8 donations that were reactive for other serological markers such as hepatitis B surface antigen (HBsAg), hepatitis B core antibody (anti-HBc), and fluorescent treponemal antibody-absorption (FTA-ABS). The overall estimated seroprevalence of other blood-borne agents among HTLV-positive blood donors was $12.3 \%$. Of the 8 donors with co-infections, 7 were reactive for hepatitis B virus serological markers (7/8; 87.5\%) (Monolisa ${ }^{\mathrm{TM}}$ HBsAg ULTRA, Monolisa ${ }^{\mathrm{TM}}$ anti-HBc PLUS Assays, BioRad, São Paulo, Brazil), and one was reactive for T. pallidum $(1 / 8 ; 12.5 \%)$. The donor who had a positive FTA-ABS test was also reactive for the Venereal Disease Research Laboratory Test. The co-infection rate was higher in men (62.5\%) than in women (37.5\%).

We found a HTLV-1 seroprevalence of $0.04-0.11 \%$ in blood donors recruited at the Regional Blood Center of Ribeirão Preto and its branches (almost the entire western part of the State of São Paulo), which is consistent with our previous study performed between 2000 and $2010^{(5)}$. Therefore, in this Brazilian region, HTLV prevalence is relatively stable. Although the overall HTLV prevalences did not differ between the studies, there were some differences within the studied municipalities of the Western part of the state. The Araçatuba and Serrana regions had prevalences of $0.10 \%$ and $0.11 \%$ respectively, which were higher than those of all of the other districts. A large community of Japanese descendants lives in Araçatuba, which could be responsible for the slightly higher HTLV prevalence. Similarly, a high HTLV-1 prevalence $(6.8 \%)$ was observed in Japanese descendants from a non-endemic area in Brazil (City of Campo Grande, mid-west Brazil) ${ }^{(6)}$. However, we could not confirm this because the ethnicity of the HTLV-positive blood donors from this locality was not collected. The higher prevalence in Serrana could be explained by the smaller sample inferred to the HTLV-positive cases.

The HTLV prevalence varies in different geographic areas, with the highest HTLV-1 prevalences in Japan, Central and Western Africa, the Caribbean, and Central and South America $^{(7)}$. The prevalence in our region was very similar to that in Central Argentina $(0.1 \%)^{(7)}$. In general, in Brazil, the HTLV1 seroprevalence varies significantly by state, and the City of 
TABLE 2 - Distribution of blood donors (2011-2014), that were processed at the Regional Blood Center of Ribeirão Preto, State of São Paulo, in the nine cities comprising the Western part of the State of São Paulo, Brazil.

\begin{tabular}{|c|c|c|c|c|c|}
\hline Blood donation branches & $\begin{array}{l}\text { Number of } \\
\text { inhabitants* }\end{array}$ & $\begin{array}{l}\text { Donors } \\
\text { (n) }\end{array}$ & $\begin{array}{l}\text { First-time } \\
\text { donors (n) }\end{array}$ & $\begin{array}{l}\text { First-time donors reactive } \\
\text { for HTLV-1/2 (n) }\end{array}$ & $\begin{array}{c}\text { HTLV-1/2 } \\
\text { seroprevalence }(\%)\end{array}$ \\
\hline Ribeirão Preto & 604,682 & 128,139 & 30,833 & 26 & 0.08 \\
\hline Franca & 318,640 & 56,811 & 12,650 & 5 & 0.04 \\
\hline Presidente Prudente & 207,610 & 59,257 & 13,598 & 11 & 0.08 \\
\hline Fernandópolis & 64,696 & 36,546 & 10,071 & 5 & 0.05 \\
\hline Batatais & 56,476 & 11,128 & 1,651 & 1 & 0.06 \\
\hline Olímpia & 50,024 & 12,592 & 2,743 & 1 & 0.04 \\
\hline
\end{tabular}

HTLV-1/2: human T-lymphotropic virus type 1 and type 2; n: number *Relative population numbers as announced by the Brazilian Institute for Geography and Statistics [Instituto Brasileiro de Geografía e Estatistica (IBGE)] for 2014.

Salvador in State of Bahia is estimated to have the highest urban prevalence in the country $(1.35 \%)^{(3)}$. During the British colonization of South Africa $\left(17^{\text {th }}-18^{\text {th }}\right.$ centuries), many Africans were captured and transported directly to Salvador. Because of this, among all of the states in Brazil, Bahia is the state with the greatest number of African descendants ${ }^{(8)(9)}$.

In the present study, the HTLV-1 prevalence was slightly higher in women (55\%) than in men (45\%), which is similar to previous findings and could be explained by the more efficient sexual transmission from men to women ${ }^{(1)(10)}$. Moreover, the age of the HTLV-1-infected blood donors varied between 19 and 63 years, and the majority $(25 / 65,38 \%)$ were young (18-29 years old). These results were not consistent with the observation that the prevalence can increase with age ${ }^{(11)}$ because in the present study, more first-time blood donors in whom HTLV infection was detected were younger. In fact, the majority of blood donors in the Regional Blood Center of Ribeirão Preto is younger (18-29 years old) which could explain our findings.

Of the HTLV-seropositive blood donors, $12.3 \%$ were serologically responsive to other bloodborne agents: $87.5 \%$ to HBV (HBsAg and anti-HBc IgG) and $12.5 \%$ to T. pallidum. A higher rate of combined HTLV-1 and HBV-seroprevalence (3.2-87.5\%) has been reported among high-risk groups such as injecting drug users (IDUs), men who have sex with men, patients with sexually transmitted diseases, female sex workers, and tuberculosis patients ${ }^{(12)}$, because HTLV and HBV have similar transmission routes (parenteral) ${ }^{(13)}$. In our previous study ${ }^{(5)}$, the prevalence of T. pallidum in HTLV-infected patients in our region was $7.7 \%$, which was much higher than that described by other studies (including the present study) ${ }^{(14)}$.

A limitation of this study was the lack of confirmatory tests to verify co-infections (HBV) in HTLV-infected individuals and to ascertain the true prevalence of co-infection. This is because, mandatory confirmatory tests for these two pathogens are not available in Brazilian blood banks.
Similar to that in other countries, infections caused by HTLV-1/2 viruses are neglected in Brazil. Currently, it is not necessary to notify the Brazilian National Sanitary Agency of newly diagnosed HTLV cases, because the infection is not considered a public health problem. Therefore, the real number of HTLV-infected individuals in Brazil and globally is widely underestimated because there are few populationbased studies, and the selected populations in which HTLV-1 infection has been detected are overrepresented. In this respect, our findings provide additional data for the prevalence of HTLV in Brazil and demonstrate the importance of regional and global hemovigilance for the infection. However, further large, multicenter studies with the general population are necessary to evaluate the real HTLV prevalence in endemic regions of the world.

\section{ACKNOWLEDGMENTS}

We are grateful to Sandra Navarro Bresciani for artwork preparation.

\section{CONFLICT OF INTEREST}

The authors declare that there is no conflict of interest.

\section{FINANCIAL SUPPORT}

This work was supported by Fundação Hemocentro de Ribeirão Preto (FUNDHERP), Centro Regional de Hemoterapia de Ribeirão Preto (CRH), Fundação de Amparo à Pesquisa do Estado de São Paulo (FAPESP), Coordenação de Aperfeiçoamento de Pessoal de Nivel Superior (CAPES), and Conselho Nacional de Desenvolvimento Científico e Tecnológico (CNPq). 


\section{REFERENCES}

1. Gessain A. Human retrovirus HTLV-1: descriptive and molecular epidemiology, origin, evolution, diagnosis and associated diseases. Bull Soc Pathol Exot 2011; 104:167-180.

2. Laperche S, Worms B, Pillonel J. Blood safety strategies for human T-cell lymphotropic virus in Europe. Vox Sang 2009; 96:104-110.

3. Galvão-Castro B, Loures L, Rodriques LG, Sereno A, Ferreira Júnior OC, Franco LG, et al. Distribution of human T-lymphotropic virus type I among blood donors: a nationwide Brazilian study. Transfusion 1997; 37:242-243.

4. Inaba S, Okochi K, Sato H, Fukada K, Kinukawa N, Nakata H, et al. Efficacy of donor screening for HTLV-I and the natural history of transfusion-transmitted infection. Transfusion 1999; 39:11041110 .

5. Pinto MT, Rodrigues ES, Malta TM, Azevedo R, Takayanagui OM, Valente VB, et al. HTLV-1/2 seroprevalence and coinfection rate in Brazilian first-time blood donors: an 11-year follow-up. Rev Inst Med Trop S Paulo 2012; 54:123-129.

6. Bandeira LM, Uehara SNO, Asato MA, Aguena GS, Maedo CM, Benites NH, et al. High Prevalence of HTLV-1 Infection among Japanese Immigrants in Non-endemic Area of Brazil. PLoS Neg1 Trop Dis 2015; 9:e0003691.

7. Gonçalves DU, Proietti FA, Ribas JGR, Araújo MG, Pinheiro $\mathrm{SR}$, Guedes AC, et al. Epidemiology, treatment, and prevention of human T-cell leukemia virus type 1-associated diseases. Clin Microbiol Rev 2010; 23:577-589.

8. Paiva A, Casseb J. Origin and prevalence of human T-lymphotropic virus type 1 (HTLV-1) and type 2 (HTLV-2) among indigenous populations in the Americas. Rev Inst Med Trop S Paulo 2015; 57:1-13.

9. Gadelha SR, Aleluia MM, Mello MAG, Rego FFA, Pereira LS, Galvão-Castro B, et al. The origin of HTLV-1 in the South Bahia by phylogenetic, mitochondrial DNA and $\beta$-globin analysis. Retrovirology 2014; 11 (suppl 1):P49.

10. Verdonck K, González E, Van Dooren S, Vandamme AM, Vanham G, Gotuzzo E. Human T-lymphotropic virus 1: recent knowledge about an ancient infection. Lancet Infect Dis 2007; 7:266-281.

11. Catalan-Soares BC, Proietti FA, Carneiro-Proietti ABF. Human T-cell lymphotropic viruses (HTLV) in the last decade (19902000): epidemiological aspects. Rev Bras Epidemiol 2001; 4:81-95.

12. Chenari M, Norouzi M, Ghalichi L, Rezaee A, Yari A, Alavian SM, et al. Characterization of overt and occult hepatitis B virus infection among HTLV-1 positive healthy carriers in the Northeast of Iran; An HTLV-I endemic area. J Med Virol 2014. DOI 10.1002/ jmv.24046.

13. Gessain A, Barin F, Vernant JC, Gout O, Maurs L, Calender A, et al. Antibodies to human T-lymphotropic virus type-I in patients with tropical spastic paraparesis. Lancet 1985; 2:407-410.

14. Ribeiro D, Rezende EF, Pinto VM, Mendes Pereira GF, Miranda AE. Prevalence of and risk factors for syphilis in Brazilian armed forces conscripts. Sex Transm Infect 2012; 88:32-34. 